\title{
Strain effects in film materials based on metals
}

\author{
Z.M. Makukha, L.V.Odnodvorets, I.Yu.Protsenko*, N.I. Shumakova \\ Department of Applied Physic, Faculty of Electronics and Informational Technologies, Sumy State University, \\ Sumy, 2, Rymskyi-Korsakov Str. 40007, Ukraine \\ *Corresponding author E-mail: protsenko@aph.sumdu.edu.ua
}

\begin{abstract}
The results of experimental and calculate studies of strain effect and magneto-strain effect in two- and multilayer film systems based on different metals with various structural and phase state was presented. For example film systems based on Fe and Pt strain effects in MOKE studies and calculated of value of the proposed strain coefficient of MOKE. For comparison was calculated of strain coefficient of giant magnetoresistance.
\end{abstract}

Keywords: film materials, strain effects, magnetoresistance, GMR, Kerr effect

\section{Introduction}

Thin film materials are widely used in sensor technique. Various aspects of this problem are analyzed in the literature. Theoretical basis of sensorika for monolayer films set in work [1] in which the features of electronic properties of metal films that are widely used in sensors of temperature, strain and Hall effect. Resulting in the equations for electrical conductivity, thermoelectric power, Hall coefficient and strain coefficient of resistivity, which takes into account all possible mechanisms of electron scattering (by phonons and defects of the crystal structure, at external surfaces of the film and at the grain boundaries) can accurately predict the electronic properties of the films. Generalization of some results on the use of single-layer polycrystalline metal films and granular alloy thin film as sensing elements microsensors carried out in work [2] (see also references cited in work [2]).

The purpose of this work is to obtain and analyze experimental results for the strain effect and magneto-strain effect in electroresistive, giant magnetoresistance (GMR), magnetooptical Kerr effect (MOKE) in two- and multilayer film systems based on different metals. The features of these film materials is that they must place an additional mechanism of electron scattering at the interfaces, which can cause both gain and attenuation of mentioned above effects.

\section{Methods of experimental research}

At the research of strain properties of film systems we used a technique which is described in detail in our earlier work [3]. During the process of the experiment we have used automated system based on ADAM-4018 - 8-channel 16-bit sigma-delta ADC using which we measured the sample resistance according to the four-point scheme; we also used USB $\rightarrow$ RS 232/422/485 ADAM-4561 interface converter, asynchronous motor, and Creative Labs Web-camera. A program developed in LabVIEW and machine vision module. One end of the substrate with system of contacts and sample was fastened in place by bracket and the opposite end was fixed to the rod of a micro-screw connected by means of a reducer to an electric motor, which can rotate either clockwise or anti-clockwise, depending on the control signals from ADAM-4068 relay-supply module. Web-camera was placed near the micro-screw and shot its images with frequency 10 frames/s. Simultaneously, with the process of micro-screw scale mark identification, readings of the sample resistance were also noted.

Methods of measuring the GMR for pseudo spin-valves, depending on the longitudinal strain is presented in work [4]. Quantitative characteristic strain effect in this case may be a coefficient $\gamma_{l}^{G M R}=\frac{1}{G M R} \cdot \frac{\Delta G M R}{\Delta \varepsilon_{l}}$. As we know, quantitative characteristic of strain effect in electrical resistance is $\gamma_{l}^{R}=\frac{1}{R} \cdot \frac{\Delta R}{\Delta \varepsilon_{l}}$, where $\varepsilon_{l}$ - longitudinal strain of the sample. By 
analogy with this strain coefficient us $[5,6]$ the corresponding coefficient magneto-strain effect $\beta_{\gamma_{l} B}=\frac{1}{\gamma_{l}} \cdot\left(\frac{\Delta \gamma_{l}}{\Delta B}\right)_{\varepsilon_{l}}$, where $B$ - induction of the external magnetic field.

Experimental studies MOKE performed in an external magnetic field during strain to $10 \%$, allowing to carry out research both in elastic (up 0.5\%) and plastic (in the range of $0.5-10 \%$ ) strain. Film samples based on Fe and Pt were prepared by layering condensation of crucibles in high vacuum of $10^{-6} \mathrm{~Pa}$ on substrate $(S)$ of polystyrene (the study of strain effects in MOKE) and single crystal silicon with a natural layer of $\mathrm{SiO}_{2}$ (measurement of magnetic properties). In this case the condensation layers took place at the $T_{s}=350 \mathrm{~K}$, which contributed to a large extent, preservation of identity of the individual layers and the formation of disordered solid solutions (s.s.), most likely took place at the interfaces.

Strain was carried out when its direction and the direction of the magnetic field lines are parallel (we denote the index $\langle l »)$ or perpendicular (index $\langle t »)$, respectively. Note that this indexing is to a large extent arbitrary and has the same meaning as in the case of strain effect. It deals with a variety of measurement geometries MOKE. As a quantitative characteristic of strain effect MOKE we proposed the coefficient $\gamma_{l}^{M O K E}=\frac{1}{\Theta_{0}} \cdot \frac{\Delta \Theta}{\Delta \varepsilon_{l}}$, where $\Theta_{0}-$ angle of the rotation of polarization plane (Kerr angle) at the $\varepsilon=0, \Delta \Theta=\Theta_{\varepsilon_{l}}-\Theta_{0}$.

Phase composition of the samples was investigated by electron microscopy and electron diffraction.

\section{Experimental results}

\subsection{The longitudinal strain coefficient}

Table 1 presents results of strain effect in two- and multilayer film systems. Systems were selected so as to consider all possible options for their structural and phase states: systems in which keep individuality separate layers; systems which formed s.s. or intermetallic phases at the interface and the system in which the formation of solid solutions throughout the volume of the sample stabilization or no stabilization of the granular state.

Analysis of the results presented in Table 1 leads to the following conclusions:

- In all cases $\gamma_{l}^{R}$ is always larger value $\left(\gamma_{l}^{R}\right)_{M e}$ for single-layer films of metals, which are components of a multilayer system, the same thickness as the whole film system;

- This suggests that the appearance of a new mechanism of electron scattering on interfaces leads to an increase $\gamma_{l}^{R}$;

- Abnormally small coefficient $\gamma_{l}^{R}$ (less than 2-3 units) occur in the case when the Poisson ratio of the sample film $\mu_{f} \geq 0.5$ (a detailed analysis of this problem made by us in [7]);

- Film systems in which a s.s. throughout the volume can be used as high-temperature sensitive element of strain sensor, since their separation is observed at very high temperatures (for example, s.s. ( $\mathrm{Fe}, \mathrm{Cr}$ ) stable, depending on the concentration, to the temperature $T=1800 \mathrm{~K}$ ); the feature of s.s. is that the solvent is a high concentration of metal, which provide a high stability;

- Film systems in which the keep of the individual separate layers can be used as sensitive elements in the range low and intermediate temperatures (up to $T=700 \mathrm{~K}$ ), because they have higher value of $\gamma_{l}^{R}$ compared to single-layer films, but they can lose their strain properties at elevated temperatures result of the occurrence of diffusion processes in multilayers;

- Film systems in which formed of s.s.or intermetallic phases at the interface can not be effective sensitive elements, as further diffusion processes and phase formation will cause the instability of their characteristics. 
Table 1: Experimental results of measurement strain coefficient

\begin{tabular}{|c|c|c|c|c|}
\hline \multirow[t]{2}{*}{ Film system } & \multirow{2}{*}{$\begin{array}{c}\text { Characteristic of film } \\
\text { system }\end{array}$} & \multicolumn{2}{|c|}{ Elastic strain } & \multirow{2}{*}{$\begin{array}{c}\text { Plastic strain } \\
\gamma_{l}^{R}\end{array}$} \\
\hline & & $\gamma_{l}^{R}$ & $\left(\gamma_{l}^{R}\right)_{M e} / \gamma_{l}^{R}$ & \\
\hline $\begin{array}{l}\mathrm{Fe}(20) / \mathrm{a}-\mathrm{Gd}(7) / \mathrm{Fe}(15) / \mathrm{S} \\
(\mathrm{a}-\text { amorphous })\end{array}$ & \multirow{7}{*}{$\begin{array}{l}\text { Keep individuality the } \\
\text { separate layers. } \\
\text { Phase composition: } \\
\mathrm{Me}_{1}+\mathrm{Me}_{2}\end{array}$} & 3.0 & - & 8.0 \\
\hline $\mathrm{Fe}(38) / \mathrm{a}-\mathrm{Gd}(25) / \mathrm{Fe}(42) / \mathrm{S}$ & & 7.0 & - & 3.0 \\
\hline $\mathrm{Fe}(7) / \mathrm{a}-\mathrm{Gd}(14) / \mathrm{Fe}(14) / \mathrm{S}$ & & 1.9 & - & 1.0 \\
\hline $\mathrm{Cu}(20) / \mathrm{Cr}(20) / \mathrm{S}$ & & 12.4 & $\left(\gamma_{l}^{R}\right)_{C u} I \gamma_{l}^{R}=0.2$ & - \\
\hline $\mathrm{Cu}(20) / \mathrm{Cr}(30) / \mathrm{S}$ & & 11.7 & $=0.2$ & - \\
\hline $\mathrm{Cu}(25) / \mathrm{Cr}(70) / \mathrm{Cu}(50) / \mathrm{S}$ & & 10.0 & - & - \\
\hline $\mathrm{Cu}(25) / \mathrm{Cr}(80) / \mathrm{Cu}(75) / \mathrm{S}$ & & 9.5 & - & - \\
\hline$[\mathrm{Ni}(50) / \mathrm{Cr}(10)]_{4} / \mathrm{S}$ & \multirow{4}{*}{$\begin{array}{c}\text { Formed phase } \\
\text { or s.s. } \\
\text { at the interfaces. } \\
\text { Phase composition: } \\
\mathrm{Me}_{1}+\mathrm{Me}_{2}+\text { intermetallic } \\
\text { phase or } \\
\mathrm{Me}_{1}+\mathrm{Me}_{2}+\text { s.s. }\left(\mathrm{Me}_{1}, \mathrm{Me}_{2}\right)\end{array}$} & 21.7 & - & - \\
\hline$[\mathrm{Ni}(50) / \mathrm{Cr}(10)]_{2} / \mathrm{S}$ & & 20.7 & - & - \\
\hline $\mathrm{Ni}(50) / \mathrm{Cr}(70) / \mathrm{S}$ & & 7.7 & - & - \\
\hline $\mathrm{Cr}(60) / \mathrm{Ni}(30) / \mathrm{S}$ & & 8.7 & - & - \\
\hline $\mathrm{Ag}(18) / \mathrm{Co}(17) / \mathrm{S}$ & \multirow{4}{*}{$\begin{array}{l}\text { Systems with limited } \\
\text { solubility of elements. } \\
\text { Phase composition: } \\
\text { FCC-Ag+HCP-Co+ } \\
\text { +s.s.(Ag,Co). }\end{array}$} & 4.2 & $\left(\gamma_{l}^{R}\right)_{C o}{ }^{l \gamma_{l}^{R}}=0.55$ & - \\
\hline $\operatorname{Ag}(22) / \mathrm{Co}(22) / \mathrm{S}$ & & 3.5 & $=0.50$ & - \\
\hline $\mathrm{Ag}(40) / \mathrm{Co}(20) / \mathrm{S}$ & & 2.4 & $=0.60$ & - \\
\hline $\mathrm{Ag}(45) / \mathrm{Co}(36) / \mathrm{S}$ & & 2.7 & $=0.42$ & - \\
\hline $\mathrm{Fe}(20) / \mathrm{Cr}(30) / \mathrm{S}$ & \multirow{5}{*}{$\begin{array}{c}\text { Formed s.s. throuth } \\
\text { sample volume. } \\
\text { Phase composition: } \\
\text { s.s. based on Fe and } \mathrm{Cr} \text { or Fe } \\
\text { and } \mathrm{Pd}\end{array}$} & 3.4 & $\left(\gamma_{l}^{R}\right)_{F e} l \gamma_{l}^{R}=0.9$ & 5.6 \\
\hline $\mathrm{Fe}(50) / \mathrm{Cr}(30) / \mathrm{S}$ & & 9.9 & $=0.9$ & 10.7 \\
\hline $\mathrm{Pd}(5) / \mathrm{Fe}(15) / \mathrm{S}$ & & 8.2 & - & - \\
\hline $\mathrm{Pd}(30) / \mathrm{Fe}(15) / \mathrm{S}$ & & 7.0 & - & - \\
\hline$[\mathrm{Pd}(5) / \mathrm{Fe}(5)]_{3} / \mathrm{S}$ & & 12.8 & - & - \\
\hline
\end{tabular}

\subsection{Magneto-strain coefficient}

As we have shown in [6] magneto-strain coefficient $\beta_{\gamma_{l}} R_{B}$ in the limiting case of the large $\gamma_{l}^{R}$ can be expressed as the ratio

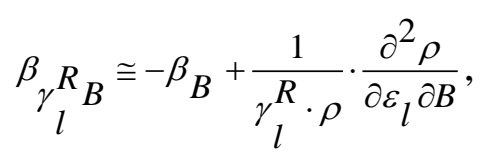

where $\beta_{B} \cong \frac{1}{\rho} \cdot \frac{\Delta \rho}{\Delta B}$ - the magnetic coefficient of resistivity.

Measuring $\beta_{B}, \gamma_{l}^{R}, \rho$ and can be calculated very important gauge characteristic $\frac{\partial^{2} \rho}{\partial \varepsilon_{l} \partial B}$ that shows how change the value $\rho$ of the simultaneous action of mechanical and magnetic fields.

In the Table 2 provides the data on $\beta_{B}$ for multilayers based on films $\mathrm{Fe}$ and $\mathrm{Cr}, \mathrm{Fe}$ and $\mathrm{Cu}$ for two measuring geometries - parallel $(\|)$ and perpendicular $(\perp)$, when the direction of current and magnetic field are parallel and lie in the plane of the substrate or when the field is directed perpendicular to the plane of the substrate. The value of magnetoresistance (MR) was calculated by the ratio $M R=\frac{R(B)-R\left(B_{S}\right)}{R\left(B_{S}\right)}$, where $B_{S}$ - the induction of saturation. 
Based on these data we can calculate the second derivative, which, for example, in the case of system $\mathrm{Cr}(30) / \mathrm{Fe}(40) / \mathrm{S}$ has a value $\frac{\partial^{2} \rho}{\partial \varepsilon_{l} \partial B} \cong-1,4.10^{-6} \mathrm{Omm}^{-1}$, and the value of $\beta_{\gamma_{l}}{ }_{B}=0.63 \mathrm{~T}^{-1}$. Note that the sensitivity of the resistivity of the film to strain $\left(S=\frac{\Delta \rho}{\Delta \varepsilon}\right.$ ) has a different value in the elastic or plastic strain. For example, with a total film thickness $\mathrm{d}=50-80 \mathrm{~nm}$ for film system $\mathrm{Fe} / \mathrm{Cr} / \mathrm{S}$ the ratio sensitivities $\frac{S_{p}}{S_{e}}=2.6-3.1$ (indices "p" and "e" correspond to plastic or elastic strain).

Table 2: The value MR and $\beta_{B}$ for multilayers

\begin{tabular}{|c|c|c|c|c|c|c|c|c|}
\hline \multirow[t]{3}{*}{ Sample } & \multicolumn{4}{|c|}{ || geometry } & \multicolumn{4}{|c|}{$\perp$ geometry } \\
\hline & \multicolumn{2}{|c|}{ non-annealing } & \multicolumn{2}{|c|}{$\begin{array}{c}\text { annealing to } \\
800 \mathrm{~K}\end{array}$} & \multicolumn{2}{|c|}{ non-annealing } & \multicolumn{2}{|c|}{$\begin{array}{l}\text { annealing to } \\
800 \mathrm{~K}\end{array}$} \\
\hline & $\begin{array}{l}\text { MR } \\
{[\%]}\end{array}$ & $\beta_{B}\left[T^{-1}\right]$ & $\begin{array}{l}\text { MR } \\
{[\%]}\end{array}$ & $\beta_{B}\left[T^{-1}\right]$ & $\begin{array}{l}\mathrm{MR} \\
{[\%]}\end{array}$ & $\beta_{B}\left[T^{-1}\right]$ & $\begin{array}{l}\mathrm{MR} \\
{[\%]}\end{array}$ & $\beta_{B}\left[T^{-1}\right]$ \\
\hline $\mathrm{Fe}(2.5) /[\mathrm{Cr}(1) / \mathrm{Fe}(2.5)]_{3} / \mathrm{S}$ & 0.35 & -5.8 & 0.41 & -6.8 & 0.42 & -7.0 & 0.49 & -8.2 \\
\hline $\mathrm{Fe}(2.5) /[\mathrm{Cr}(1) / \mathrm{Fe}(2.5)]_{7} / \mathrm{S}$ & 0.40 & -6.7 & 0.47 & -7.8 & 0.46 & -7.7 & 0.53 & -8.8 \\
\hline $\mathrm{Fe}(2.5) /[\mathrm{Cr}(1.5) / \mathrm{Fe}(2.5)]_{3} / \mathrm{S}$ & 0.12 & -2.0 & 0.48 & -8.0 & 0.04 & -0.7 & 0.10 & -1.7 \\
\hline $\mathrm{Fe}(2.5) /[\mathrm{Cr}(1.5) / \mathrm{Fe}(2.5)]_{7} / \mathrm{S}$ & 0.13 & -2.2 & 0.15 & -2.5 & 0.08 & -1.3 & 0.11 & -1.8 \\
\hline $\mathrm{Fe}(2.5) /[\mathrm{Cu}(1.5) / \mathrm{Fe}(2.5)]_{3} / \mathrm{S}$ & 0.50 & -8.3 & 0.36 & -6.0 & 0.40 & -6.7 & 0.33 & -5.5 \\
\hline $\mathrm{Fe}(2.5) /[\mathrm{Cu}(1.5) / \mathrm{Fe}(2.5)]_{9} / \mathrm{S}$ & 0.74 & -12.3 & 0.47 & -7.8 & 0.52 & -8.7 & 0.43 & -7.2 \\
\hline $\mathrm{Fe}(2.5) /[\mathrm{Cu}(2) / \mathrm{Fe}(2.5)]_{3} / \mathrm{S}$ & 0.09 & -1.5 & 0.06 & -1.0 & 0.07 & -1.2 & 0.05 & -0.8 \\
\hline $\mathrm{Fe}(2.5) /[\mathrm{Cu}(2) / \mathrm{Fe}(2.5)]_{7} / \mathrm{S}$ & 0.12 & -2.0 & 0.10 & -1.7 & 0.11 & -1.8 & 0.07 & -1.2 \\
\hline
\end{tabular}

\subsection{Strain effect on GMR}

Based on the data of work [4] for magnetoresistive properties (GMR) of pseudo spin-valve $\mathrm{Cr}(5) / \mathrm{Au}(2.5) / \mathrm{Co}(5) / \mathrm{Au}(\mathrm{x}) / \mathrm{Co}(2)$, where $x=2.2$ - $4 \mathrm{~nm}$ - the thickness of the Au film, we had made the calculation of strain coefficient $\gamma_{l}^{G M R}$. In the case of strain from 0 to $10^{-2}$ value $\gamma_{l}^{G M R}=1.5(x=2.2 \mathrm{~nm}) ;-22.7(2.4 \mathrm{~nm}) ; 0.9$ $(2.9 \mathrm{~nm}) ; 1.44(3.3 \mathrm{~nm})$ and $31.1(4 \mathrm{~nm})$.

\subsection{Strain effect on MOKE}

The methodology of our work is that by measuring the angle of the rotation plane of polarization for different values of strain and geometry measurements, it can be concluded regarding the influence of strain effects on magnetic properties of two-layer films and multilayers. Fig. 1 shows the dependence of the relative change of the Kerr angle in a wide of strain range of the sample. Note that this interval is almost completely corresponds to the plasticity as a transition from elastic to plastic strain, according to our data, the thin film s.s. based on Fe and Pt occurs at strain transition plastic $\rightarrow$ elastic $\varepsilon_{\mathrm{tr}}=0.4 \%$.

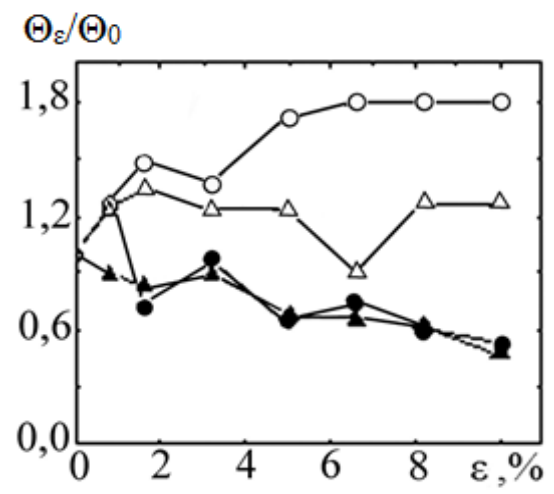

Fig. 1: Dependence of the rotation plane of polarization in the longitudinal $(\circ, \Delta)$ and transverse $(\bullet, \mathbf{\Delta})$ geometry measurements for films $\mathrm{Fe}(32) / \mathrm{Pt}(3) / \mathrm{S}(0, \bullet)$ and $[\mathrm{Fe}(3) / \mathrm{Pt}(3)]_{8} / \mathrm{S}(\Delta, \boldsymbol{\Delta})$. 
Since the magnetooptical effect in ferromagnetic is determined by the effective internal fields caused by the exchange and spin-orbit interaction, then the deformation at the microscopic level, the processes that cause change in the effective field and the resulting birefringence for ferromagnetic.

Based on ratio for $\gamma_{l}^{M O K E}$ and the results presented in Fig.1, we can calculate the value of strain coefficient of MOKE. The coefficients $\gamma_{l}^{M O K E}$ varies from 3 to 8 at the deformation $10 \%$ for samples $\mathrm{Fe}(32) / \mathrm{Pt}(3) / \mathrm{S}$ and $[\mathrm{Fe}(3) / \mathrm{Pt}(3)]_{8} / \mathrm{S}$. Note that the value $\gamma_{l}^{M O K E}$ play the same role in the strain effects of MOKE as $\gamma_{l}^{R}$ and $\gamma_{l}^{G M R}$ on the strain effect of resistance and GMR, that can be used as a working option strain sensors, which are based on the effect of MOKE.

\section{Conclusion}

Despite the relatively small value in film systems we studied some of them can be used as sensitive elements of strain sensors at the presence or absence of an external magnetic field. Application of spin-valves as sensitive strain sensor elements may be more effective at the selecting the optimum thickness of non-magnetic layer. Sensors based on the GMR effect and MOKE may be effective in measuring the strain of magnetostrictive materials.

\section{Acknowledgements}

Work carried out with financial support from the Ministry of Education and Science of Ukraine (Grant № 0112U001381).

\section{References}

[1] C.R. Tellier, "Thin metal film sensons", Active and Passive Elec. Comp., Vol.12 (1985), pp. 9 - 32.

[2] S.A. Nepijko, D.Kutnyakhov, S.I.Protsenko, L.V.Odnodvorets, G.Schonhense, "Sensor and microelectronic elements based on nanoscale granular systems (review) ", J. Nanopart. Res., Vol.13, Iss.12 (2011), pp. $6263-6281$.

[3] S.I. Protsenko, D.V. Velykodnyi, V.A. Kheraj, M.S. Desai, C.J. Panchal, I.Yu. Protsenko, "Electrophysical properties of $\mathrm{Cu} / \mathrm{Cr}$ and $\mathrm{Fe} / \mathrm{Cr}$ films systems within elastic and plastic deformation range", J. Mater. Sci., Vol. 44, №18 (2009), pp. 4905-4910.

[4] S. Luby, B. Anwarzai, V. Aĉ, E. Majkova, R. Senderak, "Pseudo spin-valve with different spacer thickness as sensing elements of mechanical strain", Vacuum, Vol.86 (2012), pp. 718 - 720.

[5] S. I. Protsenko, "Magneto-deformation effect in thin films”, J. Nano- Electron. Phys., Vol.1, №2 (2009), pp. 5-7.

[6] Z.M. Makukha, S.I. Protsenko, L.V. Odnodvorets, I.Yu. Protsenko, "Magneto-strain effect in double-layer film systems", J. Nano- Electron. Phys., Vol. 4, №2 (2012), pp. 02043-1 - 02043-3.

[7] I.Yu. Protsenko, L.V.Odnodvorets, K.V. Tyschenko, M.O. Shumakova, "Features strain properties thin-films: anomalous small of strain coefficient", JMET, Vol.1, Iss.1 (2013), pp. 35 - 40. 